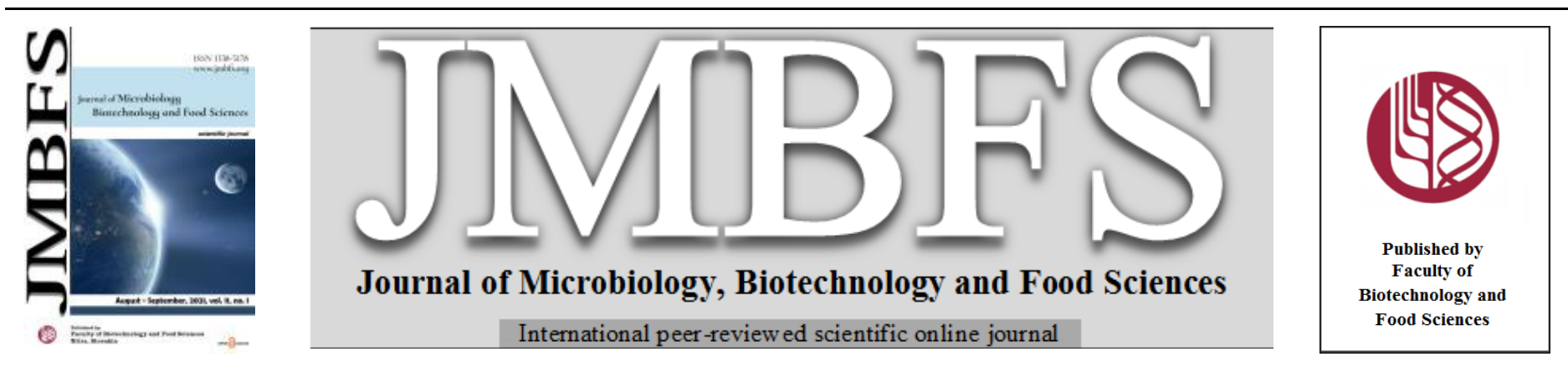

\title{
SEROTYPING AND ANTIMICROBIAL RESISTANCE OF SALMONELLA ISOLATES FROM FOOD MATRICES AND CLINICAL SPECIMENS FROM LEBANON
}

\author{
Joseph Yaghi ${ }^{1}$, Grace Narguizian ${ }^{1}$, Ali Atoui ${ }^{2}$, Marie Noel Mansour ${ }^{1}$, Malak Ghorabi ${ }^{1}$ and André EL Khoury* ${ }^{1}$ \\ Address(es): Professor André EL Khoury, \\ ${ }^{1}$ Centre d'Analyses et de Recherche (CAR), Unité de Recherche Technologies et Valorisation Agro-alimentaire (UR-TVA), Faculty of Sciences, Saint-Joseph \\ University of Beirut, Campus of sciences and technologies, Mar Roukos, Lebanon. \\ ${ }^{2}$ Laboratory of Microbiology, Department of Life and Earth Sciences, Faculty of Sciences I, Lebanese University, Hadat Campus, Beirut, Lebanon.
}

*Corresponding author: andre.khoury@usj.edu.lb

https://doi.org/10.15414/jmbfs.3565

\section{ARTICLE INFO}

Received 11. 8. 2020

Revised 11.3. 2021

Accepted 24. 3. 2021

Published 1. 8. 2021

Regular article

open $\partial_{\text {ACCESS }}$

\begin{abstract}
Salmonella is a genus of bacteria responsible for the most frequently reported cases of foodborne illnesses worldwide. In this study, serotyping was done by using highly specific manufactured antisera, to identify circulating Salmonella serovars isolated from food samples and clinical specimens. Antibiotic susceptibility testing was also performed to determine the level of resistance of these serotypes. This was done by using the disk diffusion method by testing 14 clinically important antibiotics on the Salmonella isolates. A total of 85 Salmonella strains, preidentified by biochemical testing, were collected over the course of one year. Serotyping of the isolates revealed the presence of 14 serotypes in the food samples with $S$. Infantis and $S$. Enteritidis, being the most common and 6 serotypes in the clinical samples with $S$. Enteritidis and $S$. Typhimurium being the most common. Antimicrobial susceptibility testing results showed resistance of isolates from both sample types to conventional antibiotics like ampicillin and piperacillin, and almost total resistance of the food isolates to a broad-spectrum antibiotic imipenem, belonging to the carbapenem class. Higher resistance was observed in food samples than in clinical ones. Moreover, 13 and 3 multidrug resistant serotypes of Salmonella were identified for the first time in Lebanon in the food and clinical samples respectively, with three of them isolated from imported food samples.
\end{abstract}

\section{INTRODUCTION}

Foodborne bacterial diseases constitute a growing challenge to human health around the world, in both developing and industrialized countries (Sánchezvargas et al., 2011). Case reports of food intoxications and infections caused by these pathogens are increasing as a consequence of changes in the natural environment, human lifestyle and the haphazard use and prescription of antibiotics, causing bacterial resistance and outbreaks (Scallan et al., 2011). Several pathogens like Salmonella, Escherichia coli, Yersinia enterolitica, Staphylococcus aureus, Clostridium botulinum and many more, are causing foodborne outbreaks and becoming economic burdens on many societies, as they associate with new types of food vehicles and develop resistance to common antibiotics (Masterton, 2008; Pires et al., 2014). Of these pathogens, the genus Salmonella and specifically non-typhoidal Salmonella rank second after Norovirus in the top five pathogens contributing to domestically acquired foodborne illnesses published by the CDC (Scallan et al., 2011).

The Salmonella genus encompasses many strains and serotypes that cause an array of diseases, ranging from mild gastroenteritis to life threatening major diseases like typhoid fever, caused by Salmonella Typhi and Paratyphi serotypes, especially in the poorer regions of the world and developing countries like Lebanon (Ryan et al., 2017). This genus contains more than 2,500 serotypes, at present, and has a complex nomenclature (Sloan $\boldsymbol{e t}$ al., 2017). Hence, serotype identification is of great importance in order to monitor and contain outbreaks associated with salmonellosis cases, and link them with their respective contaminated food sources for the purpose of prioritizing effective food safety interventions. Continuous updates of the identification and tracking of new serovars is of utmost importance for the long term epidemiological surveillance of this ubiquitous pathogen found in the food chain, in order to establish control in the public health sector in Lebanon (Malaeb et al., 2016).

Add to that, antibiotic resistance is actually reaching dangerously high levels in the world. New resistance mechanisms are emerging and spreading across the globe, compromising our ability to treat common infectious diseases. For an increasing number of infections, such as tuberculosis, sepsis, pneumonia, gonorrhea and foodborne diseases, treatment becomes more difficult, if not sometimes impossible, due to the loss of effectiveness of antibiotics (World Health Organization, fact sheet).

The objective of our study was to identify, by serotyping, the circulating and predominant serovars of Salmonella isolated from clinical and food sources in Lebanon, and to establish the current antibiotic resistance patterns of the identified serotypes of Salmonella

\section{MATERIALS AND METHODS}

\section{Bacterial isolates}

Clinical isolates

Over the period of one year (October 2018 - October 2019), 16 clinical isolates already identified as Salmonella . with API 20E, were collected from different hospitals, pertaining from the stools of patients with salmonellosis.

\section{Food isolates}

Also during the period from October 2018 to October 2019, a total of 69 strains of Salmonella were collected from different food matrices and identified with API 20E. They were provided by the Lebanese Agricultural Research Institute (LARI) and the Chamber of Commerce, Industry \& Agriculture at Tripoli \& North Lebanon (CCIAT).

\section{Serotyping}

Serotyping was performed by following guides and protocols published by BioRad. (n.d.-b). The detailed flowchart of Salmonella serotyping is represented in figure 1 .

The isolated Salmonella strains were streaked onto a solid Trypticase Soya Agar (TSA) (VWR International Eurolab, Barcelona, Spain), a non-selective agar medium, to obtain pure colonies. Cultures were incubated at $37^{\circ} \mathrm{C}$ for 18 hours. 


\section{Autoagglutination Test}

The auto-agglutination test was performed by mixing pure colonies with one drop of physiological water/saline $(0.85 \%)$. If auto-agglutination was observed, the strain was recorded as being unable to be serotyped.

\section{Testing with Omni-O antiserum}

All strains were tested with Salmonella Omni-O antiserum for the presumptive identification of O-agglutinable strains of Salmonella. If agglutination exists, the strain is O-agglutinable and can be further serotyped with specific antisera.

Testing for $\mathrm{O}$ Antigens

The tests for $\mathrm{O}$ Antigens (polyvalent $\mathrm{O}$ sera, monovalent $\mathrm{O}$ sera and Anti- $\mathrm{V}$ serum) and for $\mathrm{H}$ antigen phase I and phase II (Polyvalent $\mathrm{H}$ sera and monovalent $\mathrm{H}$ sera) were done according to the bacterial serotyping guide for Salmonella (Bio-Rad, FSD_14-0699.pdf)

\section{Phase inversion - Sven Gard method}

After identification of the first phase, the Sven Gard agar medium [supplied in tubes, $25 \mathrm{~mL}$, Bio-Rad (Marnes-la-Coquette, France)] was melted in a water bath of $95^{\circ} \mathrm{C}$. After Cooling to $44^{\circ} \mathrm{C}$, one drop of SG sera, containing the agglutinin of the phase already determined, was added. Tubes were then mixed with circular motions, to ensure homogenization of the serum before pouring onto Petri-dishes. After solidification, 3 to 4 colonies from a pure culture of Salmonella were inoculated at the center of the plate and incubated, with the dish cover facing upwards, for 18 hours at $37^{\circ} \mathrm{C}$. The $\mathrm{H}$ phase II antigen was then identified by slide agglutination, by collecting the culture from the periphery of the invasion zone.
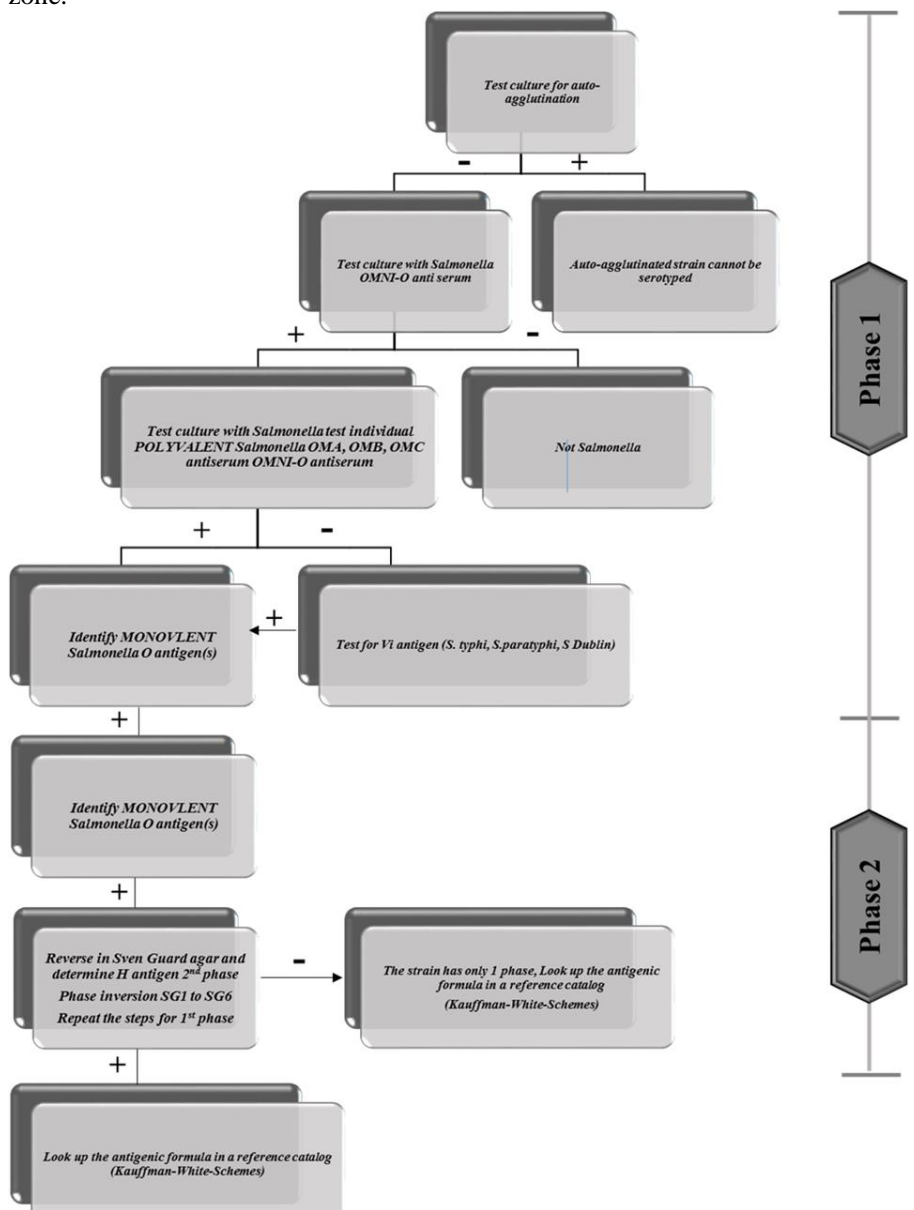

Figure 1 Detailed flowchart of Salmonella spp. serotyping (Bio-RAD, France)

\section{Identification and the Antigenic formula}

After the identification of the O, H-phase I and H-phase II antigens, they were placed in the antigenic formula to identify the serotype. This was done by referring to the White-Kauffman-Le Minor scheme (Grimont et al., 2007). The formula is as follows: $\mathrm{O}$ antigens in Arabic numeral, $\mathrm{Vi}$ (when present), $\mathrm{H}$ antigens phase $\mathrm{I}$ in lower case letters, $\mathrm{H}$ antigens phase II in Arabic numerals (when present).

The serotyping steps described previously, are summarized in the flowchart represented in figure 1.

\section{Antibiotic susceptibility testing}

Antibiotic resistance testing was performed on the serotyped strains of Salmonella (spp). by using the disk diffusion method (Kirby Bauer method) according to the guidelines of the Clinical \& Laboratory Standards Institute (CLSI) (Performance Standards for Antimicrobial Susceptibility Testing, 2017). The susceptibility testing was done using 14 antibiotics (total of seven classes) commonly used for the treatment of infections caused by Enterobacteriaceae (Table 1). Antibiotic disks were purchased from Sigma Aldrich (Darmstadt, Germany). These disks were placed on the surface of an aga plate previously inoculated with the bacterial strain and plates were incubated at $37{ }^{\circ} \mathrm{C}$ for 18 hours. After the incubation period, zones of inhibition were recorded using a ruler to the nearest millimeter and classified as resistant (R), intermediate (I) or susceptible (S) based on the guidelines of the Clinical \& Laboratory Standards Institute (CLSI) (Performance Standards for Antimicrobial Susceptibility Testing, 2017).

Table 1 List of Antibiotics used for the study

\begin{tabular}{lcc}
\hline Antibiotics & Family & Abbreviations \\
\hline $\begin{array}{l}\text { Amoxicillin-clavulanic acid } \\
(20 / 10 \mu \mathrm{g})\end{array}$ & $\begin{array}{c}\beta \text { Lactam } / \beta \\
\text { Lactamase inhibitor }\end{array}$ & AMC \\
\hline Amikacin $(30 \mu \mathrm{g})$ & Aminoglycosides & AK \\
\hline Ampicillin $(10 \mu \mathrm{g})$ & Penicillins & AMP \\
\hline Aztreonam $(30 \mu \mathrm{g}$ & Monobactams & ATM \\
\hline Ciprofloxacin $(5 \mu \mathrm{g})$ & Fluoroquinones & CIP \\
\hline Cefamandole $(30 \mu \mathrm{g})$ & Cephalosporins & MA \\
\hline Ceftriaxone $(30 \mu \mathrm{g})$ & $\begin{array}{c}\text { Third generation } \\
\text { Cephalosporins }\end{array}$ & CRO \\
\hline Imipenem $(10 \mu \mathrm{g})$ & Carbapenems & IMI \\
\hline Gentamycin $(10 \mu \mathrm{g})$ & Aminoglycosides & CN \\
\hline Ofloxacin $(5 \mu \mathrm{g})$ & Fluoroquinones & OFX \\
\hline Piperacillin $(100 \mu \mathrm{g})$ & Penicillins & PRL \\
\hline $\begin{array}{l}\text { Piperacillin - Tazobactam } \\
(100 / 10 \mu \mathrm{g})\end{array}$ & $\begin{array}{c}\beta \text { Lactam } / \beta \\
\text { Lactamase inhibitor }\end{array}$ & TZP \\
\hline Tobramycin $(10 \mu \mathrm{g})$ & Aminoglycosides & TOB \\
\hline $\begin{array}{l}\text { Trimethoprim } \\
\text { Sulfamethoxazole }(1.25 / 23.75\end{array}$ & $\begin{array}{c}\text { Folate pathway } \\
\text { inhibitors }\end{array}$ & SXT \\
\hline$\mu$ g) & &
\end{tabular}

\section{RESULTS AND DISCUSSION}

\section{Serotyping}

Serotyping of the clinical samples showed a high prevalence of $S$. Enteritidis $(56.25 \%)$ being the most commonly isolated serovar, Followed by $S$ Typhimurium (12.50\%) being the second most isolated one (Figure 2). However, the most prevalent serotype in the food samples was $S$. Infantis (24.63\%) followed by $S$. Enteritidis (18.84\%) (Figure 3).

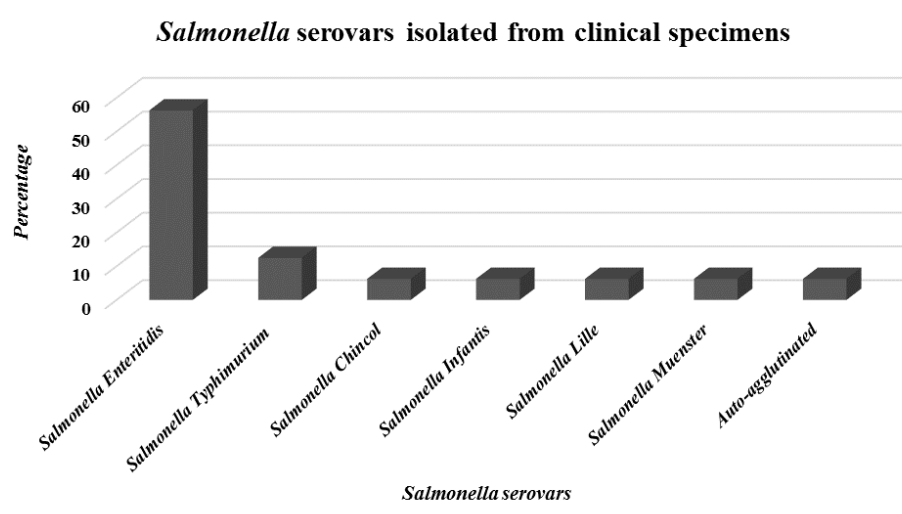

Figure 2 Percentage of Salmonella serovars isolated from clinical specimens 


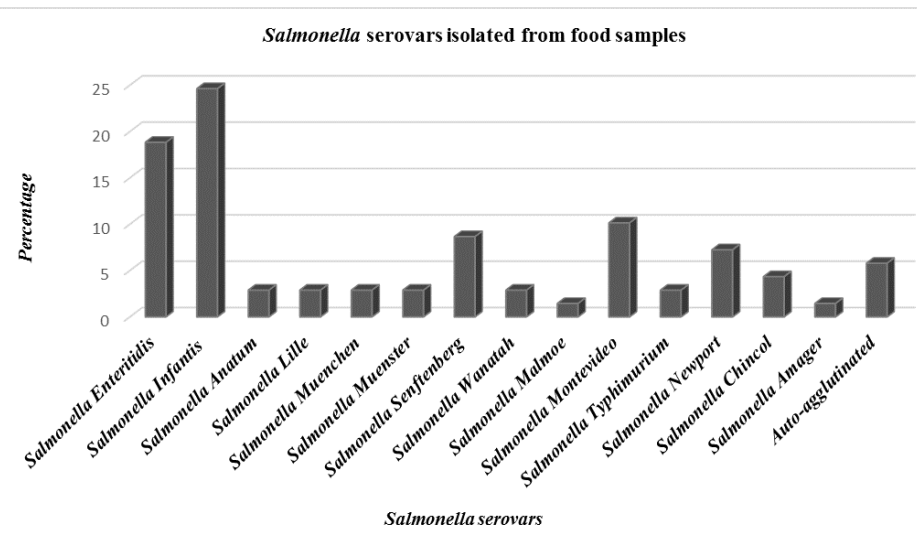

Figure 3 Percentage of Salmonella serovars isolated from food samples

Food samples showed more variety in serotypes like $S$. Montevideo, $S$. Senftenberg, S. Newport, S. Anatum, S. Muenchen, S. Wanatah (Figure 3). Sources Data of all Salmonella serovars from local and imported food matrices are shown in table 2. Chicken followed by beef, Tahina and sausages, were shown to be the most prevalent food sources of isolated Salmonella serovars. Of all the food origins, three food types are widely consumed by the Lebanese population as traditional cuisine: chicken Tawouk, raw meat and minced meat. $S$. Enteritidis was mostly isolated from chicken "Tawouk"; a traditional Middle Eastern food consisting of chicken cubes marinated in tomato paste and different spices, and minced meat. As for $S$. Infantis, this serovar was isolated from chicken dishes that can contain eggs in their breading, and ham in their filling; hence, source attribution for $S$. Infantis can be uncertain since this serotype can be isolated from chicken, eggs and swine. All the other serotypes in our study are mainly associated with their common reservoirs. The antigenic formula of the identified Salmonella serovars from clinical and food samples are represented in table 3 .

Table 2 Food sources of the serotypes Salmonella serovars from local and imported food items

\begin{tabular}{|c|c|}
\hline Serotypes & Food sources \\
\hline \multirow{4}{*}{ Salmonella Enteritidis } & Escalope (chicken) \\
\hline & Tawouk chicken \\
\hline & Minced meat \\
\hline & Chicken breast \\
\hline \multirow{5}{*}{ Salmonella Infantis } & Chicken feet \\
\hline & Chicken nuggets \\
\hline & Cordon bleu chicken \\
\hline & Chicken slices \\
\hline & Tawouk \\
\hline \multirow{3}{*}{ Salmonella Muenster } & Minced meat \\
\hline & Raw meat \\
\hline & Tahina \\
\hline \multirow{2}{*}{ Salmonella Senftenberg } & Tahina \\
\hline & Frozen beef \\
\hline \multirow{2}{*}{ Salmonella Lille } & Broiler chicken \\
\hline & Chicken breast \\
\hline \multirow{2}{*}{ Salmonella Anatum } & Soujouk (sausage) \\
\hline & Hamburger (beef) \\
\hline Salmonella Wanatah & Frozen chicken breast \\
\hline Salmonella Muenchen & $\begin{array}{l}\text { Frozen chicken breast imported from } \\
\text { Brazil }\end{array}$ \\
\hline Salmonella Typhimurium & Minced meat \\
\hline Salmonella Montevideo & Sausage \\
\hline Salmonella Malmoe & Frozen beef imported from India \\
\hline Other & $\begin{array}{c}\text { Frozen chicken breast } \\
\text { Raw meat } \\
\text { Soujouk (Sausage) } \\
\end{array}$ \\
\hline
\end{tabular}

The serotyping results of the clinical samples of this study are in agreement with the study of Fadlallah et al. (2017), who performed the serotyping of Salmonella spp. isolates, collected between 2011 and 2014 in Lebanon. Their study showed the prevalence of S. Enteritidis among both human and food samples, with $S$ Typhimurium being the second prevalent serotype in both types of samples.

However, in our study, the first most prevalent serotype in the food samples was S. Infantis $(24.63 \%)$ and S. Enteritidis $(18.84 \%)$ had a lower prevalence, but still being the most commonly isolated serotype when added to the clinical serovars in term of percentages. The shift in prevalence from S. Typhimurium to S. Infantis is noted in many recent studies. The main reason can be explained by the emergence of new S. Infantis clones that have enhanced capabilities to colonize food animals, and spread rapidly (kalaba et al., 2017; Antunes et al., 2016).
Table 3 The antigenic formula of Salmonella serovars from clinical and food samples

\section{$\begin{array}{lll}\text { Nomenclature } & \text { OMNI-O Antigenic Formula }\end{array}$}

\begin{tabular}{lcc}
\hline Salmonella Enteritidis & + & $1,9,12: \mathrm{g}, \mathrm{m}:-$ \\
\hline Salmonella Infantis & + & $6,7,14: \mathrm{r}: 1,5$ \\
\hline Salmonella Montevideo & + & $6,7,14: \mathrm{g}, \mathrm{m},[\mathrm{p}], \mathrm{s}:[1,2,7]$ \\
\hline Salmonella Senftenberg & + & $1,3,19: \mathrm{g},[\mathrm{s}], \mathrm{t}:-$ \\
\hline Salmonella Newport & + & $6,8,20: \mathrm{h}: 1,2$ \\
\hline Salmonella Typhimurium & + & $1,4,[5], 12: \mathrm{i}: 1,2$ \\
\hline Salmonella Chincol & + & $6,8: \mathrm{g}, \mathrm{m},[\mathrm{s}]:[\mathrm{e}, \mathrm{n}, \mathrm{x}]$ \\
\hline Salmonella Lille & + & $6,7,14: \mathrm{z} 38:-$ \\
\hline Salmonella Amager & + & $3,10,15: \mathrm{y}: 1,2$ \\
\hline Salmonella Malmoe & + & $6,8: \mathrm{i}: 1,7$ \\
\hline Salmonella Wanatah & + & $1,3,19: \mathrm{d}: 1,7$ \\
\hline Salmonella Muenchen & + & $6,8: \mathrm{d}: 1,2$ \\
\hline Salmonella Muenster & + & $3,\{10\}\{15\}\{15,34\}: \mathrm{e}, \mathrm{h}: 1,5$ \\
\hline Salmonella Anatum & + & $3,10,15: \mathrm{h}: 1,6$ \\
\hline
\end{tabular}

Food samples showed more variety in serotypes, with most of them not identified in the clinical samples. All the serotypes isolated from food samples, excluding $S$. Wanatah, do cause illness in humans, however, a reason for not finding them in our clinical samples might be due to the difference in sampling sizes, with food isolates $(n=69)$ being more numerous than the clinical samples $(n=16)$. The five strains that were not serotyped and were labeled as "Auto-agglutinated" (for both clinical and food samples).

By comparing the serotypes that were found in our study, and the ones identified by Fadlallah et al. (2017), we notice the absence of most serotypes like $S$. Typhi, $S$. Braenderup, $S$. Blockley and $S$. Paratyphi A in our food samples. However, lack of food source data, along with the country or region of origin, in their study, makes it difficult to compare to our samples which contained serotypes that are less commonly isolated like $S$. Malmoe and $S$. Muenster, with the latter being an invasive serotype that can contribute to an increase in fatality rates (Andino $\boldsymbol{e} t$ al., 2015). Valuable information was deduced from the food sources of the isolates, poultry constituted the main food reservoir of the totality of food sources. This is in accordance with many studies that confirm poultry as the main reservoir responsible for Salmonella spp. outbreaks (Andino et al., 2015) Furthermore, the countries of origin of the foods also revealed that four imported food items found in this study contained three different serovars $S$. Senftenberg India, $S$. Malmoe - India, and $S$. Muenchen - Brazil, with the two latter being uncommon serotypes.

\section{Antibiotic susceptibility testing}

\section{Clinical strain}

From the 16 clinical isolates, 13 were resistant to at least one antimicrobial agent from 14 tested antibiotic agents. All the isolates were susceptible to aztreonam (ATM). Almost total susceptibility was also observed for ciprofloxacin and ofloxacin (OFX) $(93.75 \%$ each). In addition, $87.5 \%$ of the isolates were susceptible to amoxicilin - clavulanic acid (AMC) and $81.25 \%$ of the isolates in this study were susceptible to both trimethoprim - sulfamethoxazole (SXT) and gentamycin $(\mathrm{CN})$. Moreover, $6.25 \%$ of the isolates were susceptible to piperacillin and $25 \%$ were susceptible to ampicillin; both belonging to the penicillin antibiotic class. However, the use of piperacillin with a $\beta$ lactamase inhibitor like tazobactam (TZP) increased the percentage of the susceptible isolates $(75 \%)$. Of particular note, none of the isolates was susceptible to imipenem (IMI) (Table 4)

The antimicrobial resistance profile of the clinical isolates is shown in table 5 . Results showed that three out of the 16 strains (18.75\%) exhibited multidrug resistance profile (MDR), defined as resistance to at least three different families of antimicrobials. $S$. Lille displayed resistance to 5 antibiotic families and 7 antimicrobial agents, and was intermediate for a 6th antibiotic class also. $S$ chincol and the autoagglutinated strain displayed resistance to 6 and 5 antimicrobial agents respectively (Table 5). 
Table 4 Percentage of Susceptible (S), Intermediate (I) or Resistant (R) serotypes isolated from clinical samples ( $\mathrm{n}=16)$ for 14 antibiotics

\begin{tabular}{lccc}
\hline \multirow{2}{*}{ Antibiotics } & \multicolumn{3}{c}{ Percentage (S, I, R) for each antibiotic } \\
\cline { 2 - 4 } & $\mathrm{S} \%$ & $\mathrm{I} \%$ & $\mathrm{R} \%$ \\
\hline AMC & 87.5 & 0 & 12.5 \\
\hline AK & 75 & 25 & 0 \\
\hline AMP & 25 & 37.5 & 37.5 \\
\hline ATM & 100 & 0 & 0 \\
\hline CIP & 93.75 & 6.25 & 0 \\
\hline MA & 87.5 & 6.25 & 6.25 \\
\hline CRO & 62.5 & 18.75 & 18.75 \\
\hline IMI & 0 & 62.5 & 37.5 \\
\hline CN & 81.25 & 12.5 & 6.25 \\
\hline OFX & 93.75 & 6.25 & 0 \\
\hline PRL & 6.25 & 31.25 & 62.5 \\
\hline TZP & 75 & 12.5 & 12.5 \\
\hline TOB & 87.5 & 6.25 & 6.25 \\
\hline SXT & 81.25 & 6.25 & 12.5 \\
\hline
\end{tabular}

Table 5 Antimicrobial resistance phenotypes of Salmonella from clinical sources and the presence of multidrug resistance (MDR) strains

\begin{tabular}{lcc}
\hline Resistance phenotypes & $\begin{array}{c}\text { Serotype (number of } \\
\text { strain) }\end{array}$ & MDR \\
\hline IMI & $S$. Enteritidis $(n=2)$ & - \\
\hline PRL & $\begin{array}{c}S . \text { Enteritidis }(n=2) \\
S . \text { Typhimurium }(n=1) \\
\text { S. Infantis }(n=1)\end{array}$ & - \\
\hline AMP-PRL & $S$. Enteritidis $(n=1)$ & - \\
\hline CRO-CN & $S$. Enteritidis $(n=1)$ & - \\
\hline AMC-AMP-PRL & $S$. Typhimurium $(n=1)$ & - \\
\hline AMP-IMI-PRL & $S$. Enteritidis $(n=1)$ & - \\
\hline AMC-AMP-CRO-IMI-PRL & Autoagglutinated $(n=1)$ & + \\
\hline AMP-MA-IMI-PRL-TZP-SXT & $S$. Chincol $(n=1)$ & + \\
\hline AMP-CRO-IMI-PRL-TZP-TOB- & $S$. Lille $(n=1)$ & + \\
SXT & & \\
\hline
\end{tabular}

\section{Food strains}

Results of antimicrobial susceptibility testing of Salmonella isolates from food are summarized in Table 6. Results showed that most of the isolates were susceptible to aztreonam (ATM) $(95.31 \%)$, ceftriaxone $(87.5 \%)$, cefamandole (MA) $(85.94 \%$ ), trimethoprim sulfamethoxazole (SXT) $(85.94 \%)$ and amoxicillin clavulanic acid (AMC) $(71.88 \%)$. Strains were commonly resistant to imipenem (IMI) $(79.69 \%)$ and showed resistance to ampicillin $(50 \%)$ and piperacillin $(25 \%)$. As for the clinical isolates, none of the food isolates was susceptible to imipenem (Table 6).

The table 7 show the antimicrobial resistance profile of food isolates where 58 among the 69 tested isolates, show a resistance to at least one family of the tested antibiotics. Among these isolates, 13 showed MDR profile (Table 7). MDR isolates were $S$. Senftenberg $(\mathrm{n}=2), S$. Anatum $(\mathrm{n}=1), S$. Newport $(\mathrm{n}=1), S$ Muenster $(\mathrm{n}=1), S$. Montevideo $(\mathrm{n}=1), S$. Chincol $(\mathrm{n}=2), S$. Infantis $(\mathrm{n}=1)$, Autoagglutinated $(\mathrm{n}=1), S$. Malmoe $(\mathrm{n}=1)$ and $S$. Muenchen $(\mathrm{n}=2)($ Table 7$)$.

Table 6 Percentage of Susceptible (S), Intermediate (I) or Resistant (R) serotypes isolated from food samples $(\mathrm{n}=64)$ for 14 antibiotics

\begin{tabular}{lccc}
\hline \multirow{2}{*}{ Antibiotics } & \multicolumn{3}{c}{ Percentage $(\mathbf{S}, \mathbf{I}, \mathbf{R})$ for each antibiotic } \\
\cline { 2 - 4 } & $\mathrm{S}(\%)$ & $\mathrm{I}(\%)$ & $\mathrm{R}(\%)$ \\
\hline AMC & 71.87 & 12.5 & 15.63 \\
\hline AK & 60.93 & 28.13 & 10.94 \\
\hline AMP & 20.31 & 29.69 & 50 \\
\hline ATM & 95.32 & 0 & 4.68 \\
\hline CIP & 73.44 & 25 & 1.56 \\
\hline MA & 85.94 & 7.81 & 6.25 \\
\hline CRO & 87.5 & 7.81 & 4.69 \\
\hline IMI & 0 & 20.31 & 79.69 \\
\hline CN & 73.43 & 15.63 & 10.93 \\
\hline OFX & 78.13 & 15.62 & 6.25 \\
\hline PRL & 20.31 & 54.69 & 25 \\
\hline TZP & 34.37 & 48.44 & 17.19 \\
\hline TOB & 76.56 & 21.88 & 3.12 \\
\hline SXT & 85.94 & 10.94 & \\
\hline
\end{tabular}


serotypes included the serotypes $S$. Muenchen, $S$. Malmoe and $S$. Senftenberg with the first two serotypes found in three imported food samples. According to the CDC, $S$. Muenchen is a commonly isolated MDR strain from South America (Brazil), and $S$. Senftenberg is considered a serotype that has higher resistance to heat up to $70{ }^{\circ} \mathrm{C}$ (Manas et al., 2003). It has a thermotolerance approximately 30 times more than $S$. Typhimurium, hence surviving high cooking temperatures and transmission to humans.

By importing food, a variety of uncommon and MDR serovars of Salmonella are being introduced into the country, these strains have increased virulence and a high potential for survival and spreading to humans through the food chain, hence increasing the dissemination of more virulent serotypes of Salmonella in Lebanon and creating possible endemic outbreak situations.

Infection with MDR Salmonella strains would result in an increased number of treatment failures, since the normally used antibiotics are no longer effective Physicians later would have to use "last resort" antibiotics that are often more expensive and toxic (Kolár et al., 2001; Papp-Wallace et al., 2011; EFSA, 2008).

\section{CONCLUSION}

Globalization of food-animal production is currently causing a major impact in antimicrobial resistance of zoonotic bacteria like Salmonella (Hur et al., 2012, Silbergeld et al., 2008). Selective pressure caused by the usage of clinically important antibiotics in feed animals to avoid animal sickness or as growth promoters, is leading to a rise in MDR isolates in animals and consequent dissemination of these strains in all the food chain (Kolár et al., 2001; Angulo e al., 2004). This can be an explanation to why the mean percent resistance in food samples was higher than the one for clinical samples in this study. These resistant bacteria are reaching humans by food consumption and causing major infections with a limited number of antibiotics to cure them. This is mostly observed in poultry production, which is one of the most consumed and increasing globally traded meat products, hence, it is crucial to restrict global usage of antibiotics in veterinary and farm settings to minimize the selection of resistant Salmonella (Hur et al., 2012; Kalaba et al., 2017).

Antibiotic susceptibility testing is an important tool to keep track of antibiotic resistance levels in various microorganisms, in different countries and throughout the world. This surveillance tool enables us to notice that resistance to antibiotics has risen greatly and quickly over the years, it also helps to identify MDR pathogens capable of fast dissemination (Jorgensen et al., 2009; Percival et al., 2014). Such knowledge allows us to focus on the development of new and improved antibiotics and alternative strategies to manage and prevent the spread of infectious foodborne diseases (Kerr et al., 2005).

Acknowledgments: The authors are very thankful to Dr. Rima EL HAJJ, head of the laboratory of microbiology at the Lebanese Agricultural Research Institute (LARI) and Dr. Khaled EL OMARI, Head of laboratories at the Chamber of Commerce, Industry \& Agriculture at Tripoli \& North Lebanon (CCIAT) for providing the Salmonella isolates. The authors also gratefully acknowledge the research council of Saint - Joseph University of Beirut for the financial support of this study (Project FS149).

\section{REFERENCES}

Andino, A., \& Hanning, I. (2015). Salmonella enterica: Survival, Colonization, and Virulence Differences among Serovars. The Scientific World Journal, 2015, 1-16. http://dx.doi.org/10.1155/2015/520179

Angulo, F. J., Nargund, V. N., \& Chiller, T. C. (2004). Evidence of an Association Between Use of Anti-microbial Agents in Food Animals and Antimicrobial Resistance Among Bacteria Isolated from Humans and the Human Health Consequences of Such Resistance. Journal of Veterinary Medicine Series B, 51(8-9), 374-379. http://dx.doi.org/10.1111/j.1439-0450.2004.00789.x

Antunes, P., Mourão, J., Campos, J., \& Peixe, L. (2016). Salmonellosis: the role of poultry meat. Clinical Microbiology and Infection, 22(2), 110-121. http://dx.doi.org/10.1016/j.cmi.2015.12.004

Bio-Rad. (n.d.-b). Bacterial Serotyping Guide for Salmonella. http://www.biorad.com/webroot/web/pdf/fsd/literature/FSD_14-0699.pdf.

Center for Disease Control and Prevention (CDC) NARMS Now: Human Data. https://wwwn.cdc.gov/narmsnow/

Clinical \& Laboratory Standards Institute (CLSI) (Performance Standards for Antimicrobial Susceptibility Testing) M100 ， 27 ${ }^{\text {th }}$ Edition .2017 http://file.qums.ac.ir/repository/mmrc/clsi\%202017.pdf

EFSA (2008). Overview of methods for source attribution for human illness from food-borne microbiological hazards - Scientific Opinion of the Panel on Biological Hazards. EFSA Journal, 6(7) http://dx.doi.org/10.2903/j.efsa.2008.764

Fadlallah, S. M., Shehab, M., Cheaito, K., Saleh, M., Ghosn, N., Ammar, W., Matar, G. M. (2017). Molecular epidemiology and antimicrobial resistance of Salmonella species from clinical specimens and food Items in Lebanon. The Journal of Infection in Developing Countries, 11(01), 19-27. http://dx.doi.org/10.3855/jidc.7786
Grimont, P. A. D., Grimont, F., \& Bouvet, P. (2007). Taxonomy of the genus Salmonella. Salmonella in Domestic Animals., 1-17. http://dx.doi.org/10.1079/9780851992617.0001

Hur, J., Jawale, C., \& Lee, J. H. (2012). Antimicrobial resistance of Salmonella isolated from food animals: A review. Food Research International, 45(2), 819830. http://dx.doi.org/10.1016/j.foodres.2011.05.014

Jorgensen, J. H., \& Ferraro, M. J. (2009). Antimicrobial Susceptibility Testing: A Review of General Principles and Contemporary Practices. Clinical Infectious Diseases, 49(11), 1749-1755. http://dx.doi.org/10.1086/647952

Kalaba, V., Golić, B., Sladojević, Ž. \& Kalaba, D. (2017). Incidence of Salmonella Infantis in poultry meat and products and the resistance of isolates to antimicrobials. IOP Conference Series: Earth and Environmental Science, 85 012082. http://dx.doi.org/10.1088/1755-1315/85/1/012082

Kerr, J. R. (2005). Antibiotic treatment and susceptibility testing. Journal of Clinical Pathology, 58(8), 786-787. http://dx.doi.org/10.1136/jcp.2005.030411

Koláŕ, M., Urbánek, K., \& Látal, T. (2001). Antibiotic selective pressure and development of bacterial resistance. International Journal of Antimicrobial Agents, 17(5), 357-363. http://dx.doi.org/10.1016/s0924-8579(01)00317-x

Malaeb, M., bizri, A. R., ghosn, N., berry, A., \& Musharrafieh, U. (2016) Salmonella burden in Lebanon. Epidemiology and Infection, 144(8), 1761-1769. http://dx.doi.org/10.1017/s0950268815003076

Mañas, P., Pagán, R., Alvarez, I., \& Condón Usón, S. (2003). Survival of Salmonella senftenberg $775 \mathrm{~W}$ to current liquid whole egg pasteurization treatments. Food Microbiology, 20(5), 593-600. http://dx.doi.org/10.1016/s0740 0020(02)00088-6

Masterton, R. (2008). The Importance and Future of Antimicrobial Surveillance Studies. Clinical Infectious Diseases, 47(S1), S21-S31. http://dx.doi.org/10.1086/590063

Papp-Wallace, K. M., Endimiani, A., Taracila, M. A., \& Bonomo, R. A. (2011). Carbapenems: Past, Present, and Future. Antimicrobial Agents and Chemotherapy, 55(11), 4943-4960. http://dx.doi.org/10.1128/aac.00296-11

Percival, S. L., \& Williams, D. W. (2014). Salmonella. Microbiology of Waterborne Diseases, 209-222. http://dx.doi.org/10.1016/b978-0-12-4158467.00010-x

Pires, S. M., Vieira, A. R., Hald, T., \& Cole, D. (2014). Source Attribution of Human Salmonellosis: An Overview of Methods and Estimates. Foodborne Pathogens and Disease, 11(9), 667-676. http://dx.doi.org/10.1089/fpd.2014.1744 Ryan, M. P., O'Dwyer, J., \& Adley, C. C. (2017). Evaluation of the Complex Nomenclature of the Clinically and Veterinary Significant Pathogen Salmonella. BioMed Research International, 2017, 1-6. http://dx.doi.org/10.1155/2017/3782182

Sánchez-Vargas, F. M., Abu-El-Haija, M. A., \& Gómez-Duarte, O. G. (2011) Salmonella infections: An update on epidemiology, management, and prevention. Travel Medicine and Infectious Disease, 9(6), 263-277. http://dx.doi.org/10.1016/i.tmaid.2011.11.001

Scallan, E., Hoekstra, R. M., Angulo, F. J., Tauxe, R. V., Widdowson, M.-A. Roy, S. L., ... Griffin, P. M. (2011). Foodborne Illness Acquired in the United States-Major Pathogens. Emerging Infectious Diseases, 17(1), 7-15. http://dx.doi.org/10.3201/eid1701.p11101

Silbergeld, E. K., Graham, J., \& Price, L. B. (2008). Industrial Food Animal Production, Antimicrobial Resistance, and Human Health. Annual Review of Public Health, 29(1), 151-169. http://dx.doi.org/10.1146/annurev.publhealth.29.020907.090904

Sloan, A., Wang, G., \& Cheng, K. (2017). Traditional approaches versus mass spectrometry in bacterial identification and typing. Clinica Chimica Acta, 473 180-185. http://dx.doi.org/10.1016/j.cca.2017.08.035

Su, L.-H., Chiu, C.-H., Chu, C., \& Ou, J. T. (2004). Antimicrobial Resistance in Nontyphoid Salmonella Serotypes: A Global Challenge. Clinical Infectious Diseases, 39(4), 546-551. http://dx.doi.org/10.1086/422726

World Health Organization, WHO, Fact sheet: https://www.who.int/newsroom/fact-sheets/detail/antibiotic-resistance 